The Effects of ALA Accreditation Standards on Library Education Programs Accredited by the

American Library Association

Michael E. Mounce

Assistant Professor

Delta State University

Contact Information:

Michael E. Mounce

Delta State University

Roberts-LaForge Library

Cleveland, MS 38733

Phone: 662-846-4457

Fax: 662-846-4443

E-mail: mmounce@deltastate.edu 


\title{
The Effects of ALA Accreditation Standards on Library Education Programs Accredited by the American Library Association
}

\begin{abstract}
This article presents the results of a survey that focused on the perceived effects of the six American Library Association (ALA) accreditation standards on ALA accredited library education programs in the United States. The standards as they pertain to specific aspects of the programs are as follows: Standard 1 missions, goals, and objectives; Standard 2 curriculum; Standard 3 faculty; Standard 4 students; Standard 5 administration and financial support; and Standard 6 physical resources and facilities (ALA 2000). In order to conduct the survey, a questionnaire was developed and e-mailed to the deans or chairs of the forty-nine ALA accredited library education programs in the United States. Those who did not respond to the questionnaire were e-mailed a second time. The questionnaire asked respondents to provide their opinions regarding the effects of ALA accreditation standards on their programs. Also, they were asked to provide the following information: location within the United States, the number of full-time equivalents (FTEs) enrolled, and the age of their programs. Out of the forty-nine recipients, there were twenty-five respondents (51 percent). Conclusions drawn from the study were that the six ALA accreditation standards combined were perceived as having more influence overall than the individual standards. Although the conclusions of the study were predictable, the study had significance since it provided specific information and data regarding professional perceptions of ALA accreditation and library education programs.
\end{abstract}

\section{Introduction}

The American Library Association (ALA) is an organization that accredits library education programs. ALA accreditation is described as a process 
for evaluating these programs for quality in the accomplishment of their objectives through the effective use of resources. This process occurs through the application of standards used to evaluate such aspects of the programs as missions, goals, and objectives. There are forty-nine ALA accredited library education programs within the United States, including Hawaii and Puerto Rico. (American Library Association [ALA], 2000).

There is much disagreement among library and information science professionals regarding the significance of ALA accreditation on library education. Some have suggested that it does indeed have influential power while others argue that it does not (Kniffel, 1999). The purpose of this article is to present the results of a study regarding ALA accreditation and its perceived effects on ALA accredited library education programs in the United States. The study sought to shed some light on this complex issue and to help clear away some of the confusion resulting from the disagreements. The study was conducted by soliciting responses from the deans or chairs of library education programs to survey questions regarding the perceived effects of the ALA's six accreditation standards on library education programs. The six standards as they pertain to specific aspects of these programs are as follows: Standard 1 mission, goals, and objectives; Standard 2 curriculum; Standard 3 faculty; Standard 4 students; Standard 5 administration and financial support; and Standard 6 physical resources and facilities (ALA, 2000). Standard 1 evaluates a program in regard to its accomplishment of program missions, goals, and objectives and Standard 2 evaluates a program in regard to its curriculum's ability to transform students into professionals, its flexibility in regard to students' goals, and its inclusion of technology. Evaluation criteria for Standard 3 include faculty duties and diversity while Standard 4 evaluates programs in regard to student diversity, the application of admission standards, and the opportunities given to students to participate in library organizations. Standard 5 evaluates programs in regard to 
the library education program directors' status and their ability to have salaries, titles, status and authority comparable to those of the heads of other departments within their institutions. Also, Standard 5 evaluates programs in regard to financial support provided by the parent institution. Standard 6 evaluates programs in regard to providing access to necessary resources and facilities as well as offering alternative modes of course delivery, such as the online mode. This study also analyzes these standards' effects in regard to the following variables: location within the United States, number of full-time equivalents (FTEs) enrolled, and age of the library education programs.

\section{Related Literature}

There are a limited number of topical articles and published empirical studies directly related to ALA standards for accreditation. Kniffel (1999) discusses such various issues as the apparent lack of preparation of students for certain areas of librarianship and the need to "provide quality distance education" and the technology to enhance such education. These issues are related to ALA Standards 2 (Curriculum) and 6 (Physical Resources and Facilities). ALA accreditation and its relevance to librarianship is also discussed in this article (Kniffel, 1999). This present study is closely related to Kniffel's article since it also discusses ALA accreditation and provides quantitative data regarding ALA Standards 2 and 6 and these standards' perceived influence on the curriculum and physical resources of ALA accredited library education programs in the United States. Watkins discussed an issue related to Standard 2 flexibility in student curriculum in regard to student goals using the University of Michigan library education program as an example (Watkins, 1994). This study provides quantitative data in regard to the perceived influence of ALA accreditation on curriculum flexibility.

In 1996, an article reporting the results of a survey focusing on library education_programs and their characteristics was published in The Journal of 
Education for Library and Information Science. The article, written by Rebecca Watson-Boone and Darlene Wiengand, discusses the results of a survey in which thirty-five ALA accredited library education programs participated. In this survey, heads of library education programs were asked to rank seventy characteristics of their own programs according to a scale of importance to know. The scale included four categories: essential to know, high importance in knowing, low importance in knowing and not important to know. The characteristics were measured in terms of how important they were to know for the purpose of evaluating library education programs (Watson-Boone and Weingand, 1996). The present study is related to the Watson-Boone and Weingand article since both address the issue of accreditation. This study and the article both suggest that accreditation is a top priority in library education programs. According to the Watson-Boone article survey results, accreditation status was ranked by deans as the most important thing to know when evaluating a library school program. The survey results of the article also indicate that accreditation status was highly ranked by the ALA Committee on Accreditation, institutional administrators, library school alumni and library employers. According to the survey results of this study, seventy-six percent of the respondents indicated that ALA accreditation standards have at least a moderate level of influence on ALA accredited library education programs. Fifty-six percent of the respondents indicated that the standards have very much influence while twenty percent indicated a moderate level of influence.

As is also true in the present study, topics related to all six ALA accreditation standards are included in the results of the Watson-Boone and Weingand article. In the article results, topics in the "essential to know" category are found relating to Standards 2, 3, 4, and 5 respectively: the speed with which technologies become a part of the curriculum, faculty involvement in research, admission standards and the visibility of the program director on campus. Topics 
related to Standard 1, such as goals and objectives of the program, are found in the "high importance in knowing" category. Those related to Standard 6 are found in the categories of "low importance in knowing" and "not important to know" categories. In the "low importance" category, there was the topic of physical facilities of the school. The topic of availability of the programs through distance education modes was found in the "not important" category (Watson-Boone and Weingand, 1996).

\section{Methodology}

The present study involved conducting a survey of ALA accredited library education programs in the United States with deans or chairs as participants. A cover letter and a questionnaire containing a total of nineteen questions were e-mailed to library education program directors. E-mail was chosen as the method for obtaining answers for the questionnaire since it was deemed to be an efficient and effective mode of communication. E-mail addresses of program directors were located on the Web sites of the library education programs. Phone interviews and personal interviews were not preferred since phone calls can be intrusive and in-person interviews are costly and time consuming. Regular mail was not chosen for the delivery of questionnaires because of cost and time.

The first, second, and third questions of the survey dealt with the following topics respectively: locations within the United States, the number of FTEs enrolled in the programs and the age of the programs. It should be noted that some respondents left the second and third questions blank. In order to insert the missing factual data for the second question, the ALISE Library and Information Science Education Statistical Report 2000 was consulted. The third question was supplemented by the necessary information provided on the academic institutions' Web sites. Survey questions four through eighteen focused on the ALA accreditation standards and the influence they have on surveyed 
library education programs and certain aspects of these programs. The nineteenth question was open-ended and gave respondents an opportunity to provide additional comments.

For survey questions four through eighteen, respondents were asked to give their answers according to a scale of influence. The scale included the following categories: very much, a moderate amount, very little and none. A "not sure" option was also included. For example, a respondent may have answered "very much" to the question "In your opinion, how much influence does Standard 1 have on this library education program's pursuit of its mission and goals?." This would indicate that the respondent believes that Standard 1 has a significant influence on his or her program's mission and goal pursuits.

Survey questions four and five focused on Standard 1 and its influence on the programs' missions, goals and objectives. The sixth, seventh and eighth survey questions focused on the influence of Standard 2 on the programs' curriculum. Standard three's influence on the programs' faculty was the focus of survey questions nine and ten, while survey questions eleven, twelve and thirteen focused on Standard 4 and its influence on the programs' students. Survey questions fourteen and fifteen pertained to the influence of Standard 5 on the programs' administration and financial support. The influence of Standard 6 on the programs' physical resources and facilities was the focus of survey questions sixteen and seventeen. Survey question eighteen focused on the combined influence of all of the standards on the surveyed programs.

As previously stated, survey instruments were e-mailed to the directors of library education programs. Recipients who did not respond to the first e-mailing were sent a second request. A total of twenty-five responses were received. A copy of the survey instrument is presented in the appendix.

\section{Outcomes of the Study}

Survey question one inquired about the location of the programs within 
the United States. For the twenty-five responses, six programs were in the North Central region, five in the North East, four in the West, and ten in the South. Question two asked for the number of full-time equivalent (FTE) students enrolled in the program. Results indicate four programs have fewer than 100 FTEs, six have between 100 and 200, twelve have between 200 and 300, and three have 300 or more. Question 3 requested information on the age of the program. Eight programs had been in existence fewer than fifty years, thirteen had been in existence between fifty and 100 years, and four had been in existence 100 years or more.

The factors of location within the United States, number of full-time equivalent (FTE) students, and age of the programs were included in this study since they may affect library education programs in various ways. The factor of location of a program, for example, may affect student or faculty diversity. The length of existence (age) of a program may affect such aspects of a program as contributing to improving its mission, goals and objectives. The number of FTEs within a program could affect such aspects as financial support provided by the parent institution.

In this study, the factors of location within the United States, number of FTEs and age of library education programs were analyzed in regard to the influence of ALA accreditation on respondents' library education programs. In regard to regional location, the standards were perceived as having very much influence in the Northeast and South regions. Three of the five directors responded "very much" in the Northeast, while six of the ten respondents in the South region responded within this category. In the North Central region, the general perception was that the standards have very much to a moderate amount of influence on the programs. Five of the six respondents in this region answered within these categories. This implies that the influence of the standards may be slightly less in the North Central region than in the other two mentioned regions. 
The West region, however, was not found to have a general perception. None of the influence categories contained a majority of the four responses. Two directors answered "very much," while the other two responded "a moderate amount" and "very little."

In regard to the factor of the number of FTEs, the perceptions were that the standards have very much to a moderate amount of influence on the programs. The general perception in the less than 100 FTEs group was that the standards have very much to a moderate amount of influence. All four of the respondents in this group answered within these categories. Respondents in the 100-199 FTEs and 200-299 FTEs groups generally perceived the standards as having very much influence. Four of the six respondents in the former group answered "very much," while seven out of twelve gave this response in the latter group. This implies that the standards may have slightly less influence in the less than 100 FTEs group than in the other two groups. There was no general perception found in the 300 or more FTEs group. Each of the three responses in this group differed in relation to amount of influence. One responded "very much," one "a moderate amount," and one "very little."

In regard to the factor of age of the programs, it was found that the standards were generally perceived as having very much or very much to a moderate amount of influence on library education programs. In the less than 50 years program age group, six out of eight respondents answered "very much" or "a moderate amount." The responses of eight of the thirteen respondents in the 50-99 years category indicated that the standards may have slightly more influence on their programs than was indicated by the respondents in the less than 50 years category. There was no general perception found in the 100 or more years category, since the four respondents' answers were evenly divided between the "very much" and "none" categories.

Tables 1 - 7 display responses to questions four through eighteen of the 
research instrument. One table is provided for each of the six ALA standards. Table 7 provides respondents' perceptions of how much influence the six ALA accreditation standards have on the programs overall.

Table 1 provides results for questions four and five regarding the programs' missions, goals, and objectives, respectively. Results indicate that respondents believe ALA accreditation has a strong influence on their missions and goals with sixty percent responding "very much," although responses were not as strong. Seventy-two percent indicated that ALA Standard 1 at least moderately influences their objectives.

\begin{tabular}{|l|c|c|c|c|}
\hline \multicolumn{5}{|c|}{ TABLE 1 } \\
\hline & \multicolumn{5}{|c|}{ Standard 1: Mission, Goals, and Objectives } \\
\hline & Responses & Percent & Responses & Percent \\
\hline & 15 & 60 & 10 & 40 \\
\hline Very Much & 4 & 16 & 8 & 32 \\
\hline Moderate & 1 & 4 & 1 & 4 \\
\hline Very Little & 4 & 16 & 4 & 16 \\
\hline None & 1 & 4 & 2 & 8 \\
\hline Not Sure & 25 & 100 & 25 & 100 \\
\hline Total & & & & \\
\hline
\end{tabular}

Table 2 shows results for questions six (transforming students into professionals), seven (flexibility of curriculum in regard to students' goals), and eight (inclusion of technological theories and applications) relating to curriculum. Results indicate that ALA Standard 2 does exert influence on a program's curriculum issues. A large number of respondents stated that Standard 2 had "very much" influence on transforming students (forty-four percent), flexibility (thirty-two percent) and technology inclusion (twenty percent), and many of the other respondents rated influence as "moderate" for transforming students (twenty-eight percent), flexibility (thirty-six percent), and technology inclusion (forty-eight percent). 
TABLE 2

Standard 2: Curriculum

\begin{tabular}{|l|c|c|c|c|c|c|}
\hline & \multicolumn{2}{|c|}{$\begin{array}{c}\text { Student } \\
\text { Transforming }\end{array}$} & \multicolumn{2}{c|}{ Flexibility } & \multicolumn{2}{c|}{$\begin{array}{c}\text { Technology } \\
\text { Inclusion }\end{array}$} \\
\hline & Responses & Percent & Responses & Percent & Responses & Percent \\
\hline $\begin{array}{l}\text { Very } \\
\text { Much }\end{array}$ & 11 & 44 & 8 & 32 & 5 & 20 \\
\hline Moderate & 7 & 28 & 9 & 36 & 12 & 48 \\
\hline $\begin{array}{l}\text { Very } \\
\text { Little }\end{array}$ & 2 & 8 & 3 & 12 & 3 & 12 \\
\hline None & 3 & 12 & 4 & 16 & 4 & 16 \\
\hline Not Sure & 2 & 8 & 1 & 4 & 1 & 4 \\
\hline Total & 25 & 100 & 25 & 100 & 25 & 100 \\
\hline
\end{tabular}

Table 3 presents the data gathered from questions nine and ten pertaining to Standard 3 and the amount of influence it is perceived to have on the duties and diversity of faculty within the surveyed library education programs. Similar to Standards 1 and 2, Standard 3 appears to have a significant influence on the duties and diversity of faculty. Thirty-six percent of respondents indicated that Standard 3 "very much" influences the teaching, research, and service duties of faculty while 24 percent indicated that the standard "very much" influences the recruitment of faculty from a variety of cultural and ethnic backgrounds.

\begin{tabular}{|l|c|c|c|c|}
\hline \multicolumn{5}{|c|}{ TABLE 3 } \\
Standard 3: Faculty \\
\hline & \multicolumn{2}{|c|}{ Duties } & \multicolumn{2}{c|}{ Diversity } \\
\hline & Responses & Percent & Responses & Percent \\
\hline Very Much & 9 & 36 & 6 & 24 \\
\hline Moderate & 8 & 32 & 10 & 40 \\
\hline Very Little & 4 & 16 & 5 & 20 \\
\hline None & 3 & 12 & 3 & 12 \\
\hline Not Sure & 1 & 4 & 1 & 4 \\
\hline Total & 25 & 100 & 25 & 100 \\
\hline
\end{tabular}

Questions eleven, twelve and thirteen relate to Standard 4 and its influence over a program's recruitment of students from a variety of cultural and ethnic backgrounds, the way in which admission standards are applied in the program, and the opportunities given to students to participate in library-related 
organizations. Table 4 shows that the "moderate" influence category was the one with the most responses in regard to diversity in student recruitment and the application of admission standards. The data of Table 4 also indicate that Standard 4 has "very little" to "moderate" influence on the students" opportunities for organization participation.

\begin{tabular}{|l|c|c|c|c|c|c|}
\hline \multicolumn{7}{|c|}{ TABLE 4 } \\
\multicolumn{7}{|c|}{ Standard 4: Students } \\
\hline & Diversity & \multicolumn{2}{c|}{ Admissions } & \multicolumn{2}{c|}{ Organizations } \\
\hline & Responses & Percent & Responses & Percent & Responses & Percent \\
\hline $\begin{array}{l}\text { Very } \\
\text { Much }\end{array}$ & 5 & 20 & 5 & 20 & 4 & 16 \\
\hline Moderate & 10 & 40 & 11 & 44 & 7 & 28 \\
\hline $\begin{array}{l}\text { Very } \\
\text { Little }\end{array}$ & 5 & 20 & 3 & 12 & 9 & 36 \\
\hline None & 4 & 16 & 4 & 16 & 3 & 12 \\
\hline Not Sure & 1 & 4 & 2 & 8 & 2 & 8 \\
\hline Total & 25 & 100 & 25 & 100 & 25 & 100 \\
\hline
\end{tabular}

Table 5 contains the data collected from the respondents pertaining to Standard 5. Question fourteen solicited information about the amount of influence it has on the respondents' salary, title, status and authority in comparison with those of heads of other academic programs in their institutions and question fifteen solicited information about the financial support provided by the parent institutions. The data of Table 5 suggests that the general perception was that Standard 5 has "moderate" to "very little" influence on equal status and "moderate" influence on financial support.

\begin{tabular}{|l|c|c|c|c|}
\hline \multicolumn{5}{|c|}{ TABLE 5 } \\
\hline & \multicolumn{7}{|c|}{ Standard 5: Administration and Financial Support } \\
\hline & Responses & Percent & Responses & Percent \\
\hline Very Much & 3 & 13 & 5 & 21 \\
\hline Moderate & 6 & 26 & 10 & 41 \\
\hline Very Little & 7 & 30 & 4 & 17 \\
\hline None & 4 & 18 & 4 & 17 \\
\hline Not Sure & 3 & 13 & 1 & 4 \\
\hline Total & 23 & 100 & 24 & 100 \\
\hline
\end{tabular}


Questions sixteen and seventeen related to the influence of Standard 6 on the program's access to physical resources and facilities that meet the academic needs of students and faculty and the program's alternative modes of course delivery such as interactive video networking and online resources and facilities. According to the data of Table 6, Standard 6 is generally perceived as having a "moderate" level of influence on access and "moderate" to "very little" influence in regard to delivery mode.

\begin{tabular}{|l|c|c|c|c|}
\hline \multicolumn{5}{|c|}{ TABLE 6 } \\
& Standard 6: Physical Resources and Facilities \\
\hline & \multicolumn{2}{|c|}{ Access } & \multicolumn{2}{c|}{ Delivery Modes } \\
\hline & Responses & Percent & Responses & Percent \\
\hline Very Much & 6 & 24 & 3 & 13 \\
\hline Moderate & 9 & 36 & 6 & 25 \\
\hline Very Little & 6 & 24 & 9 & 37 \\
\hline None & 3 & 12 & 5 & 21 \\
\hline Not Sure & 1 & 4 & 1 & 4 \\
\hline Total & 25 & 100 & 24 & 100 \\
\hline
\end{tabular}

Question eighteen asked the respondents to give their opinion regarding how much influence all of the ALA accreditation standards have on their programs overall. As illustrated in Table 7, the majority of respondents perceived the standards as having "very much" influence on their programs. One notable point is that in this category all responses to the questions were certain responses. All the other areas had at least one "not sure" response.

\begin{tabular}{|l|c|c|}
\hline \multicolumn{3}{|c|}{$\begin{array}{c}\text { TABLE 7 } \\
\text { Overall Influence }\end{array}$} \\
\hline & Responses & Percent \\
\hline Very Much & 14 & 56 \\
\hline Moderate & 5 & 20 \\
\hline Very Little & 4 & 16 \\
\hline None & 2 & 8 \\
\hline Not Sure & 0 & 0 \\
\hline Total & 25 & 100 \\
\hline
\end{tabular}

It should be noted that there were several comments made in response to question nineteen in regard to all the standards. Some comments seem to confirm 
that the standards have a high level of influence on the programs. For example, one director stated that "the standards are particularly important to us so that we can retain our reputation in L.S." Other comments suggest that the standards may not have as much influence as the numbers in Table 7 suggest. For example, a program director stated "in most cases we do not make decisions about what we will do because of the standards." However, even those who claimed that they would do what they do without the standards acknowledged that they were "useful" "a help" and "important."

\section{Conclusions and Recommendations}

One conclusion drawn from this study was that the ALA accreditation standards were perceived as being more influential overall than in specific areas. This conclusion is supported by data presented in the tables. According to Table 7 , for example, as many as fifty-six percent of the total respondents stated that all the ALA accreditation standards combined have very much influence on their programs overall. According to Tables 1-6, which display the data pertaining to the perceived influence of the individual standards, Standard 1, relating to missions and goals, was the only standard perceived as having "very much" influence by a majority of respondents (sixty percent). This was, however, the only variable so perceived by a majority. For the other variables studied, three showed the most frequent response to be "very much": Standard 1, Objectives (forty percent); Standard 2, Student Transforming (forty-four percent); and Standard 3, Duties (thirty-six percent). Of the other ten variables, seven had "moderate" as the most frequent response: Standard 2, Flexibility (thirty-six percent); Standard 2, Technology Inclusion (forty-eight percent); Standard 3, Faculty Diversity (forty percent); Standard 4, Student Diversity (forty percent); Standard 4, Admissions (forty-four percent); Standard 5, Financial Support (forty-one percent); Standard 6, Access (thirty-six percent). Three of the variables had "very little" as the most frequent response: Standard 4, 
Organizations (thirty-six percent); Standard 5, Equal Status (thirty percent); Standard 6, Delivery Modes (thirty-seven percent). When compared to the data of Table 7, the data pertaining to the fourteen variables in Tables 1-6 indicate that the standards may not be as influential in particular as they are in general. Furthermore, most of the comments made in response to question nineteen were in regard to all of the standards, not to one or two particular standards.

Another conclusion drawn from the study was that the standards were perceived as having a positive influence on the surveyed programs. This conclusion was drawn from some comments made in response to question nineteen, which credit the standards for good program reputations, helping programs to keep current, and other benefits. For example, in addition to the comment already cited that the standards assist programs in retaining their library science reputation, another director stated that the standards "keep us in touch with the profession." Several directors stated that the standards were "useful" "a help" and "important."

From this study, a few recommendations can be made regarding to the study of ALA accreditation and its effects on ALA accredited library education programs. First, it is recommended that the scope of coverage could be broadened to include the ALA accredited programs in Canada which were not included in this study. Second, a comparative study could be conducted to compare the influence of ALA accreditation standards on library education programs with the influence of the parent institutions on these programs. 


\section{References}

American Library Association. (2003, August 28). Standards for accreditation of master's

programs in library and information studies 1992. Retrieved December 4, 2003, from http://www.ala.org/Content/NavigationMenu /Our_Association/Offices/ Accreditation1/standards4/standards.htm

Kniffel, L. (1999, June/July). Practitioners, educators seek library's place in professional education, April 30- May 1, in Washington. American Libraries, 30, 12-15.

Watkins, B. T. (1994, May). New era for library schools. The Chronicle of Higher

Education, 40, A19-A20.

Watson-Boone, R., \& Weingand, D. (1996, Winter). Deans rank indicators of effectiveness for schools of library and information studies. The Journal of Education for Library and Information Science, 37, 30-43. 


\section{Appendix}

\section{QUESTIONNAIRE}

\section{General Questions}

1. In which state is this library education program located?

2. How many full-time equivalent students are enrolled in this program?

3. How many years has this program been in existence?

\section{Standard 1: Mission, Goals and Objectives}

4. In your opinion, how much influence does Standard 1 have on this library education program's pursuit of its mission and goals?

Not Sure Very Much

A Moderate Amount Very Little None

5. In your opinion, how much influence does Standard 1 have on the achievement of this program's objectives, which are defined as educational results to be achieved?

Not Sure

A Moderate Amount

Very Little None

\section{Standard 2: Curriculum}

6. In your opinion, how much influence does Standard 2 have on the curriculum's ability to transform students into library and information science professionals?

$\overline{\text { Not }}$ Sure

A Moderate Amount

Very Little None

7. In your opinion, how much influence does Standard 2 have on the curriculum's flexibility in regard to student's individual goals?

Not Sure A Moderate Amount Very Little None

8. In your opinion, how much influence does Standard 2 have on the curriculum's inclusion of technological theories and applications?

$\overline{\text { Not }}$ Sure

A Moderate Amount Very Little None 


\section{Standard 3: Faculty}

9. In your opinion, how much influence does Standard 3 have on the faculty's demonstrations of teaching, researching and serving in this program?

Not Sure Very Much

A Moderate Amount

Very Little None

10. In your opinion, how much influence does Standard 3 have on this program's recruitment of faculty from a variety of cultural and ethnic backgrounds?

$\overline{\text { Not }}$ Sure

A Moderate Amount Very Little None

\section{Standard 4: Students}

11. In your opinion, how much influence does Standard 4 have on this program's recruitment of students from a variety of cultural and ethnic backgrounds?

Not Sure Very Much A Moderate Amount Very Little None

12. In your opinion, how much influence does Standard 4 have on the way in which admission standards are applied in this program?

Not Sure Very Much A Moderate Amount Very Little None

13. In your opinion, how much influence does Standard 4 have on the opportunities given to students to participate in library related organizations?

$\overline{\text { Not }}$ Sure Very Much A Moderate Amount Very Little None

\section{Standard 5: Administration and Financial Support}

14. In your opinion, how much influence does Standard 5 have on your having a title, salary, status and authority that is comparable to those of heads of other academic programs in your institution?

Not Sure Very Much A Moderate Amount Very Little __ None

15. In your opinion, how much influence does Standard 5 have on this program's receiving of financial support from its parent institution?

Not Sure Very Much A Moderate Amount Very Little None

\section{Standard 6: Physical Resources and Facilities}

16. In your opinion, how much influence does Standard 6 have on this program's 
access to physical resources and facilities that meet academic needs of students and faculty?

Not Sure Very Much A Moderate Amount Very Little None

17. In your opinion, how much influence does Standard 6 have on this program's alternative modes of course delivery, such as interactive video networking and online? Very Much A Moderate Amount Very Little None Not Sure

\section{All Standards}

18. In your opinion, how much influence do the six ALA accreditation standards have on this program overall?

Not Sure A Moderate Amount __ Very Little __ None

\section{Comments}

19. Please feel free to add any comments on this subject that you would like to contribute. 